\title{
Allergic rhinitis, asthma and gastro-esophageal reflux disease: a cross-sectional study on their reciprocal relations
}

\section{Ameer Kakaje ( $\square$ ameer.kakaje@hotmail.com )}

Damascus University, Faculty of medicine https://orcid.org/0000-0002-3949-6109

Mohammad Marwan Alhalabi

Damascus University, faculty of medicine

\section{Ayham Alyousbashi}

Damascus University, faculty of medicine

\section{Ayham Ghareeb}

Damascus University, faculty of medicine

\section{Research Article}

Keywords: Allergic rhinitis, laryngopharyngeal reflux, gastro-oesophageal reflux disease, asthma, allergies, SFAR; RSI, Middle East

Posted Date: May 20th, 2020

DOl: https://doi.org/10.21203/rs.3.rs-29393/v1

License: (c) (i) This work is licensed under a Creative Commons Attribution 4.0 International License. Read Full License

Version of Record: A version of this preprint was published at Scientific Reports on February 3rd, 2021. See the published version at https://doi.org/10.1038/s41598-020-80793-1. 


\section{Abstract}

Allergic rhinitis (AR) is a very common medical condition worldwide which affects the quality of life of many for long periods throughout the year. It has many symptoms such as sneezing, a sore throat, globus pharyngeus, rhinorrhoea, congestion, and postnasal drip that may overlap with laryngopharyngeal reflux (LPR) which is a different medical condition. LPR can be considered as an extra oesophageal manifestation of gastro-oesophageal reflux disease (GORD) or a different entity altogether. LPR can go under-diagnosed as there is no definitive diagnostic tool. LPR can impose a real challenge as it may occur for years without diagnosis which can affect the quality of life even more. Having AR can also increase the chance of having asthma which is also in turn correlated with having GORD. Although AR and LPR are not life-threatening, they are persistent medical conditions, meaning they affect the everyday life and causing unnecessary distress. In this study we evaluate their correlation in Syria in the Middle East as there are not many studies on this topic. We found responders with LPR symptoms do have more AR symptoms $(P<0.001)$ and that $A R$ and $L P R$ are correlated with having asthma. We also found that $A R$ and LPR correlation is independent from having asthma $P<0.0001$ but with subjects with asthma, no such a correlation was found.

\section{Introduction}

Laryngopharyngeal reflux (LPR) is having a reflux of gastric contents that reaches the upper aerodigestive tract without having heartburn or regurgitation [1]. LPR is an atypical presentation of gastro-oesophageal reflux disease (GORD) or can be considered a different entity [2]. LPR and GORD can have different symptoms as GORD has other signs such as heartburn and regurgitation that increase at night and when supine and having oesophagitis on endoscopy or abnormal pH monitoring [1, 3]. In contrast, LPR diagnosis can be much more complicated with many methods from interviews to challenging treatment methods as LPR has many vague and unspecific symptoms such as throat clearing, globus pharyngeus, and hoarseness [3-5]. Many risk factors for GORD were studied such as having asthma which was found by meta-analysis to be correlated with GORD [6].

Allergic rhinitis (AR) is one of the most common diseases worldwide; it is an inflammation that occurs in the nasal mucosa due to allergens exposure [7]. AR prevalence ranges from $5 \%$ to $22 \%$ worldwide [8]. However, a survey in the Middle East found that $10 \%$ of responders had AR [9]. Although AR is not lifethreatening, AR affects the quality of life, and is a common risk factor for multiple airway conditions [1013]. AR and asthma can be viewed as two corresponding airway diseases as they have common traits [14]. AR has a wide variety of symptoms including sneezing, a sore throat, globus pharyngeus, rhinorrhoea and congestion, and postnasal drip $[15,16]$. As AR and LPR have many symptoms in common resulting from irritation to the aerodigestive tract, they may have a correlation as suggested in many studies regardless of having asthma $[17,18]$. In this study we used a validated reflux symptom index (RSI) in Arabic [5, 19-22] to assess LPR and an Arabic version of the score for allergic rhinitis (SFAR) $[23,24]$ to assess AR in Syria and to find if such a correlation exists. 


\section{Methods And Materials}

Online surveys were used so we can cover the largest population possible. Informed consent was taken for participating in the research, and for using and publishing of the data. Demographic questions were asked such as gender and age and questions about other comorbidities. We used a form of RSI which was validated in Arabic [22]. RSI is a self-administered questionnaire which relies on a scoring system for symptoms that evaluate the possibility of LPR and the cut-off point was set as 13 or more to suggest the possibility of LPR $[5,19]$. We also used an Arabic version of SFAR, a simple self-reported tool and the cutoff point was $7[23,24]$. These symptoms included: hoarseness, throat clearing, mucus in the throat, difficulty of swallowing, coughing after lying down or eating, difficulties of breathing, annoying cough, globus pharyngeus and heartburn. The scale ranged from 0 when answering "no problem" to 5 when answering "severe problem" for each item. The total score ranged from 0 to 45 . This study protocol was approved by Damascus University, faculty of medicine and was conducted online, including Syrians from all cities.

Data were processed using IBM SPSS software version 26 for Windows (SPSS Inc, IL, USA). Chi-square was performed to determine statistical significance between the groups. Pearson correlation coefficient was calculated for the groups. Odds ratios (ORs) and the $95 \%$ confidence intervals were also calculated for the groups using Mantel-Haenszel test by using the same software. Values of less than 0.05 for the two-tailed $P$ values were considered statistically significant.

\section{Results}

The study had 673 subjects ( 170 males and 503 females) with a mean age of $23.92 \pm 6.620$. SFAR and RSI questionnaires were disturbed to all subjects with the result that $341(50.7 \%)$ subjects had AR according to SFAR and 212 (31.5\%) subjects had LPR according to RSI. We compared subjects with negative and positive final results (Table 1 ) and found that having positive symptoms that suggest LPR was correlated with having AR suggestive tests $\mathrm{P}<0.0001$ (OR, 2.592; 95\% Cl 1.846-3.639).

Comparing each SFAR item with positive and negative LPR is demonstrated in Table 2. Having positive LPR was significantly correlated with sneezing, runny nose, blocked nose, nasal symptoms with itchy eyes, time of occurrence, triggers, perceived allergic status, previous medical diagnosis, familial history of allergy and father history of allergy $P<0.05$. When excluding subjects with asthma, we found a statistically significant difference when having LPR being also correlated with AR despite excluding asthma $\mathrm{P}<0.0001$ (OR, 2.454; 95\% Cl 1.724-3.492). However, if we only included subjects with positive asthma, no significant correlation was found when comparing having AR or LPR P>0.05 (Table 1). Having asthma was correlated with LPR P $=0.0002$ (OR 3.096; 95\% Cl 1.665-5.759) and with AR $P<0.0001$ (OR 6.772; 95\% Cl 2.823-16.248). When bivariate Pearson correlation was used to compare the scores of SFAR and RSI, a significant positive moderate correlation was found $r=0.334$ (Figure 1) and another significant positive moderate correlation $r=0.316$ when excluding asthma (Figure 2 ). However, no significant correlation was found when comparing RSI and SFAR in subjects with asthma 
P>0.05.Comparing between each RSI item and positive and negative SFAR is demonstrated in table 3 . Having positive SFAR is positively correlated with having more LPR symptoms, including sore throat, sputum production, excessive secretions, dysphagia, coughing after eating, sleeping and lying down, breathing difficulties, extreme coughing episodes, a sense of foreign body in the throat, Epigastric Burning Sense, Chest Pain, Indigestion, and GORD $(P<0.001)$. Having asthma was correlated with higher $R S I$ and SFAR scores $(P<0.001)$.

RSI mean score was $10.50 \pm 9.085$ (CI 95\%: $9.83-11.25)$ and SFAR mean score was $6.72 \pm 3.560$ (95\% Cl: $6.45,7.00)$. In subjects with positive LPR in RSI, SFAR mean score was $8.08 \pm 3.290$ (Cl 95\% 7.63, 8.53) with $141(66.5 \%)$ subjects (CI 95\%: 59.9, 73.1) having positive AR according to SFAR. In subjects with positive AR in SFAR, RSI mean score was $13.00 \pm 9.705$ (CI 95\%: 12.04, 14.03) with 141 (41.3\%) subjects (CI 95\%: $36.1 \%, 46.9 \%)$ having positive LPR according to RSI. In subjects with asthma, SFAR mean score was $10.50 \pm 2.841$ (CI 95\%: 9.64, 11.29), and RSI mean score was $16.14 \pm 11.645$ (CI 95\%: 13.14, 19.73). When excluding asthma patients, SFAR mean score was $6.45 \pm 3.455$ (Cl 95\%: 6.19, 6.73), and SFAR mean score was $10.11 \pm 8.756$ (CI 95\%: 9.49, 10.78). Therefore, asthma subjects had higher RSI and SFAR scores $(P<0.001)$.

\section{Discussion}

LPR diagnosis has many methods that are used for diagnosis; such as throat biopsies [25], and 24-hour oropharyngeal pH monitoring [26]. Noninstrumental methods can also be used such as RSI and the reflux finding score (RFS) $[5,19]$, but they cannot be used as the gold standard to diagnose LPR. AR can be diagnosed by accurate history taking of allergy symptoms and diagnostic tests that may involve Ig-E detection, hypersensitive skin tests and nasal challenge tests [27]. Skin-prick testing had only moderate accuracy and had a huge financial burden on health systems [28]. This can justify using questionnairebased diagnostic tools as their accuracy is acceptable and much cheaper than diagnostic tests, especially in developing countries. And in our study we used the RSI and SFAR questionnaires to determine the prevalence of these diseases and suggesting the need for more accurate diagnosis.

One study found that about $25 \%$ of patients who had AR also had asthma. Having asthma was also correlated with having much more incidence for AR [29]. Two older studies found that having AR increases the chance of acquiring asthma by threefold and that AR diagnosis was mostly made before asthma presentation $[30,31]$. Furthermore, if AR was not aggressively treated early, there would be a higher chance of acquiring asthma [27]. Our study found that asthma also increased the incidence for AR by sixfold and the result was statistically significant. Asthma correlation with GORD can be explained by the fact that in asthma patients, coughing and increasing intra-abdominal pressure may induce GORD and that also in GORD patients, gastric reflux exposure can directly damage pulmonary tree, causing bronchoconstriction [32-36]. We found that asthma was significantly correlated with LPR as patients with asthma had a threefold increase in the incidence for LPR in our subjects. As the larynx exists in a critical 
location that connects upper and lower airways which all have the same microscopic structure, it is suggested that having a disease in one portion of this system would affect the entire respiratory system [37]. This could explain having asthma is correlated with having nasal symptoms and that allergy causes laryngeal irritation similarly to $A R[38,39]$. AR and allergic laryngitis (AL) can have similar manifestations [40] and as AR/AL and LPR can have overlapping symptoms, distinguishing them was proven difficult in one small study and can have no difference [15]. In our study, SFAR and RSI scores were significantly higher in subjects with asthma, indicating asthma is correlated with having more symptoms of LPR and AR. However, if we only included subjects with asthma, no significant correlation was found between LPR and AR.

If a correlation between respiratory tract disorders and GORD was to be made, certain criteria should be met: both disorders should occur more simultaneously when compared with the general population with a plausible mechanism that can explain how GORD caused such a correlation and patients should be relieved when anti-reflux therapies are used [41]. A causal link between GORD and AR was not established and only a few studies indicated a correlation [42]. We found in our study that LPR and AR occurred simultaneously more frequently as having LPR increased the incidence for AR by more than two folds which is similar to other studies $[17,18]$. Having asthma increased the correlation, but the correlation persisted even when excluding asthma which concurs with another study [18]. We also found that subjects with asthma had higher LPR and AR symptom scores which are similar to the study [18]. Mast cells release histamine as a result of GORD which might promote lower-oesophageal dysfunction [43]. Another crucial component of allergic reaction is Eosinophils which are found more in the mucosa of oesophagus in GORD patients [44]. GORD in addition to Rhinitis in general are among the main causes of chronic cough, and their role has been discussed in several studies; increased reoccurrence of the cough with reflux symptom has also been reported in more than a few patients with GORD and in those with rhinitis who do not have symptoms of GORD, indicating that other factors contribute to the development of chronic cough. In addition, the coexistence of GORD and chronic rhinosinusitis (CRS) were reported by multiple studies $[17,18,41,42,45,46]$. One theory explaining this phenomena is that Helicobacter pylori, which is usually found in the gastric mucosa and promotes heartburning, can exist in the sinonasal cavity [47]. Another theory correlated GORD with bronchial spasm [46, 48]. However, one study suggested that GORD would only worsen nasal symptom scores but did not cause chronic rhinosinusitis [46]. Studies data are conflicting in role of PPI in LPR as some studies found a higher response when using PPI suggesting complex patterns of LPR, while others did not show additional relief of symptoms compared with placebo [49] although a positive correlation was found between pH Ryan score and total SFAR score in another study which could be related to LPR [17]. RSI score in our study increased in responders with positive AR symptoms, suggesting that having AR increased the symptoms of LPR and vice versa, SFAR score increased with positive LPR symptoms, suggesting that having LPR increased symptoms of AR. This all also found when comparing each symptom of LPR with having AR and vice versa.

In conclusion, many studies had contradicting data for LPR and AR as their definition and methods of diagnosis may differ and overlap. We need more detailed methods for diagnosis as AR and LPR have a 
very high prevalence and their better managing may affect the quality of life for a very large population.

\section{Declarations}

Ethics approval and consent to participate:

Online informed consent was taken before proceeding with the survey for participating in the research, and for using and publishing the data. We assured to maintain confidentiality and asked no questions that might reveal the person's identity. No subjects were under age of 14. For subjects under age of 18 years, an online informed consent was taken that the guardian agreed that the subjects can participate in the survey as this method was agreed in the study protocol.

Our study protocol and ethical aspects were reviewed and approved by Damascus University deanship, Damascus, Syria.

Consent for publication:

Online consent for using and publishing the data were taken before participating in the research.

Availability of data and materials:

The data can be made available upon reasonable request.

Competing interests:

We have no conflict of interest to declare.

Funding:

We received no funding in any form.

\section{References}

1. Koufman, J.A., et al., Laryngopharyngeal Reflux: Position Statement of the Committee on Speech, Voice, and Swallowing Disorders of the American Academy of Otolaryngology-Head and Neck Surgery. Otolaryngology-Head and Neck Surgery, 2016. 127(1): p. 32-35.

2. Koufman, J.A., M.R. Amin, and M. Panetti, Prevalence of Reflux in 113 Consecutive Patients with Laryngeal and Voice Disorders. Otolaryngology-Head and Neck Surgery, 2016. 123(4): p. 385-388.

3. Pribuisiene, R., V. Uloza, and L. Jonaitis, [Typical and atypical symptoms of laryngopharyngeal reflux disease]. Medicina (Kaunas), 2002. 38(7): p. 699-705. 
4. Oelschlager, B.K., et al., Typical GERD Symptoms and Esophageal pH Monitoring Are Not Enough to Diagnose Pharyngeal Reflux. Journal of Surgical Research, 2005. 128(1): p. 55-60.

5. Belafsky, P.C., G.N. Postma, and J.A. Koufman, Validity and Reliability of the Reflux Symptom Index (RSI). Journal of Voice, 2002. 16(2): p. 274-277.

6. Havemann, B.D., C.A. Henderson, and H.B. El-Serag, The association between gastro-oesophageal reflux disease and asthma: a systematic review. Gut, 2007. 56(12): p. 1654-1664.

7. Dykewicz, M.S. and S. Fineman, Executive Summary of Joint Task Force Practice Parameters on Diagnosis and Management of Rhinitis. Annals of Allergy, Asthma \& Immunology, 1998. 81(5): p. 463-468.

8. Bernstein, J.A., Allergic and mixed rhinitis: Epidemiology and natural history. Allergy and Asthma Proceedings, 2010. 31(5): p. 365-369.

9. Abdulrahman, H., et al., Nasal Allergies in the Middle Eastern Population: Results from the "Allergies in Middle East Survey". American Journal of Rhinology \& Allergy, 2012. 26(6_suppl): p. S3-S23.

10. Nathan, R.A., The burden of allergic rhinitis. Allergy and Asthma Proceedings, 2007. 28(1): p. 3-9.

11. Woolcock, A.J., et al., The burden of asthma in Australia. Med J Aust, 2001. 175(3): p. 141-5.

12. Worldwide variation in prevalence of symptoms of asthma, allergic rhinoconjunctivitis, and atopic eczema: ISAAC. The International Study of Asthma and Allergies in Childhood (ISAAC) Steering Committee. Lancet, 1998. 351(9111): p. 1225-32.

13. Trikojat, $\mathrm{K}$., et al., Memory and multitasking performance during acute allergic inflammation in seasonal allergic rhinitis. Clinical \& Experimental Allergy, 2017. 47(4): p. 479-487.

14. Khan, D.A., Allergic rhinitis and asthma: Epidemiology and common pathophysiology. Allergy and Asthma Proceedings, 2014. 35(5): p. 357-361.

15. Randhawa, P., S. Mansuri, and J. Rubin, Is dysphonia due to allergic laryngitis being misdiagnosed as laryngopharyngeal reflux? Logopedics Phoniatrics Vocology, 2009: p. 1-5.

16. Turley, R., et al., Role of Rhinitis in Laryngitis: Another Dimension of the Unified Airway. Annals of Otology, Rhinology \& Laryngology, 2011. 120(8): p. 505-510.

17. Alharethy, S., et al., Correlation between Allergic Rhinitis and Laryngopharyngeal Reflux. BioMed Research International, 2018. 2018: p. 1-6.

18. Kung, Y.-M., et al., Allergic rhinitis is a risk factor of gastro-esophageal reflux disease regardless of the presence of asthma. Scientific Reports, 2019. 9(1).

19. Belafsky, P.C., G.N. Postma, and J.A. Koufman, The Validity and Reliability of the Reflux Finding Score (RFS). The Laryngoscope, 2001. 111(8): p. 1313-1317.

20. Wise, S.K., J.C. Wise, and J.M. DelGaudio, Gastroesophageal reflux and laryngopharyngeal reflux in patients with sleep-disordered breathing. Otolaryngology-Head and Neck Surgery, 2016. 135(2): p. 253-257.

21. Kelchner, L.N., et al., Reliability of Speech-Language Pathologist and Otolaryngologist Ratings of Laryngeal Signs of Reflux in an Asymptomatic Population Using the Reflux Finding Score. Journal of 
Voice, 2007. 21(1): p. 92-100.

22. Farahat, M., K.H. Malki, and T.A. Mesallam, Development of the Arabic Version of Reflux Symptom Index. Journal of Voice, 2012. 26(6): p. 814.e15-814.e19.

23. Annesi-Maesano, I., et al., The score for allergic rhinitis (SFAR): a simple and valid assessment method in population studies. Allergy, 2002. 57(2): p. 107-114.

24. Alharethy, S., et al., Validation of the Arabic version of the score for allergic rhinitis tool. Annals of Saudi Medicine, 2017. 37(5): p. 357-361.

25. Amin, S.M., et al., Laryngopharyngeal Reflux with Sore Throat: An Ultrastructural Study of Oropharyngeal Epithelium. Annals of Otology, Rhinology \& Laryngology, 2009. 118(5): p. 362-367.

26. Ayazi, S., et al., A New Technique for Measurement of Pharyngeal pH: Normal Values and Discriminating $p H$ Threshold. Journal of Gastrointestinal Surgery, 2009. 13(8): p. 1422-1429.

27. Varshney, J. and H. Varshney, Allergic Rhinitis: an Overview. Indian Journal of Otolaryngology and Head \& Neck Surgery, 2015. 67(2): p. 143-149.

28. Health Quality, O., Skin Testing for Allergic Rhinitis: A Health Technology Assessment. Ont Health Technol Assess Ser, 2016. 16(10): p. 1-45.

29. Compalati, E., et al., The link between allergic rhinitis and asthma: the united airways disease. Expert Review of Clinical Immunology, 2014. 6(3): p. 413-423.

30. Huovinen, E., et al., Incidence and Prevalence of Asthma Among Adult Finnish Men and Women of the Finnish Twin Cohort From 1975 to 1990, and Their Relation to Hay Fever and Chronic Bronchitis. Chest, 1999. 115(4): p. 928-936.

31. Settipane, R.J., G.W. Hagy, and G.A. Settipane, Long-Term Risk Factors for Developing Asthma and Allergic Rhinitis: A 23-Year Follow-Up Study of College Students. Allergy and Asthma Proceedings, 1994. 15(1): p. 21-25.

32. Castell, D.O. and P.F. Schnatz, Gastroesophageal Reflux Disease and Asthma. Chest, 1995. 108(5): p. 1186-1187.

33. Field, S.K., Asthma and Gastroesophageal Reflux. Chest, 2002. 121(4): p. 1024-1027.

34. Choy, D. and R. Leung, Gastro-oesophageal reflux disease and asthma. Respirology, 1997. 2(3): p. 163-168.

35. Zerbib, F., et al., Effects of Bronchial Obstruction on Lower Esophageal Sphincter Motility and Gastroesophageal Reflux in Patients with Asthma. American Journal of Respiratory and Critical Care Medicine, 2002. 166(9): p. 1206-1211.

36. Ates, F. and M.F. Vaezi, Insight Into the Relationship Between Gastroesophageal Reflux Disease and Asthma. Gastroenterol Hepatol (N Y), 2014. 10(11): p. 729-736.

37. Krouse, J.H., The Unified Airway-Conceptual Framework. Otolaryngologic Clinics of North America, 2008. 41(2): p. 257-266.

38. Jackson-Menaldi, C.A., A.I. Dzul, and R.W. Holland, Allergies and vocal fold edema: A preliminary report. Journal of Voice, 1999. 13(1): p. 113-122. 
39. Fried, M.P., The Larynx: A Multidisciplinary Approach. 1988: Little, Brown.

40. Krouse, J.H. and K.W. Altman, Rhinogenic Laryngitis, Cough, and the Unified Airway. Otolaryngologic Clinics of North America, 2010. 43(1): p. 111-121.

41. Loehrl, T.A. and T.L. Smith, Chronic sinusitis and gastroesophageal reflux: are they related? Current Opinion in Otolaryngology \& Head and Neck Surgery, 2004. 12(1): p. 18-20.

42. Katle, E.-J., J.G. Hatlebakk, and S. Steinsvåg, Gastroesophageal Reflux and Rhinosinusitis. Current Allergy and Asthma Reports, 2013. 13(2): p. 218-223.

43. Fernandez Rojas, C., et al., Oral health needs of athletes with intellectual disability in Eastern Europe: Poland, Romania and Slovenia. International Dental Journal, 2016. 66(2): p. 113-119.

44. Mahdavinia, M., et al., Basophils are elevated in nasal polyps of patients with chronic rhinosinusitis without aspirin sensitivity. Journal of Allergy and Clinical Immunology, 2014. 133(6): p. 1759-1763.

45. García-Compeán, D., et al., Prevalence of Gastroesophageal Reflux Disease in Patients with Extraesophageal Symptoms Referred from Otolaryngology, Allergy, and Cardiology Practices: A Prospective Study. Digestive Diseases, 2000. 18(3): p. 178-182.

46. Hanna, B.C. and P.J. Wormald, Gastroesophageal reflux and chronic rhinosinusitis. Current Opinion in Otolaryngology \& Head and Neck Surgery, 2012. 20(1): p. 15-18.

47. zdek, A., et al., A Possible Role of Helicobacter pylori in Chronic Rhinosinusitis: A Preliminary Report. The Laryngoscope, 2003. 113(4): p. 679-682.

48. Wong, I.W.Y., et al., Gastroesophageal Reflux Disease and Chronic Sinusitis: In Search of an Esophageal-nasal Reflex. American Journal of Rhinology \& Allergy, 2010. 24(4): p. 255-259.

49. Bytzer, P., Management of laryngopharyngeal reflux with proton pump inhibitors. Therapeutics and Clinical Risk Management, 2008. Volume 4: p. 225-233.

\section{Tables}


TABLE 1

Comparing Positive SFAR score with positive RSI score.

\begin{tabular}{|c|c|c|c|c|c|c|c|}
\hline Characteristic & $\begin{array}{c}\text { Positive } \\
\text { RSI }\end{array}$ & $\begin{array}{c}\text { Percentage (CI } \\
\text { 95\%) }\end{array}$ & $\begin{array}{c}\text { Negative } \\
\text { RSI }\end{array}$ & $\begin{array}{r}\text { Percentage } \\
95 \%)\end{array}$ & (CI & $P$ value & OR \\
\hline \multicolumn{8}{|l|}{ SFAR Score } \\
\hline $\begin{array}{l}\text { Positive SFAR score } \\
\text { Negative SFAR score }\end{array}$ & $\begin{array}{r}141 \\
71\end{array}$ & $\begin{array}{l}66.5 \\
33.5\end{array}$ & $\begin{array}{l}200 \\
261\end{array}$ & $\begin{array}{l}43.4 \\
56.6\end{array}$ & & $<0.000001$ & $\begin{array}{c}2.592(1.846- \\
3.639)\end{array}$ \\
\hline \multicolumn{8}{|c|}{ SFAR Score in subjects with } \\
\hline $\begin{array}{l}\text { Positive SFAR score } \\
\text { Negative SFAR score }\end{array}$ & $\begin{array}{r}22 \\
3\end{array}$ & $\begin{array}{l}88.0 \\
12.0\end{array}$ & $\begin{array}{c}16 \\
3\end{array}$ & $\begin{array}{r}84.2 \\
15.8\end{array}$ & & NS & $\begin{array}{c}1.375(0.245- \\
7.717)\end{array}$ \\
\hline \multicolumn{8}{|c|}{ SFAR Score in Subjects without } \\
\hline $\begin{array}{l}\text { Positive SFAR score } \\
\text { Negative SFAR score }\end{array}$ & $\begin{array}{r}119 \\
68\end{array}$ & $\begin{array}{l}63.6 \\
36.4\end{array}$ & $\begin{array}{l}184 \\
258\end{array}$ & $\begin{array}{l}41.6 \\
58.4\end{array}$ & & $<0.000001$ & $\begin{array}{c}2.454(1.724- \\
3.492)\end{array}$ \\
\hline
\end{tabular}

CI: Confidence interval. SFAR: Score for allergic rhinitis. RSI: Reflux symptom index. OR: Odds ratio. NS: Not significant.

Figures 
TABLE 2

Comparing each SFAR item with having positive or negative LPR according to RSI

\begin{tabular}{|c|c|c|c|c|c|c|}
\hline SFAR items & Positive RSI & Percentage & Negative RSI & Percentage & $P$ value & OR (CI=95\%) \\
\hline \multicolumn{7}{|l|}{ Sneezing } \\
\hline Negative & 91 & 42.9 & 267 & 57.9 & \multirow[t]{2}{*}{0.0003} & \multirow[t]{2}{*}{$1.830(1.317-2.543)$} \\
\hline Positive & 121 & 57.1 & 194 & 42.1 & & \\
\hline \multicolumn{7}{|l|}{ Runny Nose } \\
\hline Negative & 88 & 41.6 & 234 & 50.8 & \multirow[t]{2}{*}{0.026} & \multirow[t]{2}{*}{$1.453(1.046-2.018)$} \\
\hline Positive & 124 & 58.4 & 227 & 49.2 & & \\
\hline \multicolumn{7}{|c|}{ Blocked Nose } \\
\hline Negative & 63 & 29.7 & 240 & 52.1 & \multirow[t]{2}{*}{$<0.0001$} & \multirow[t]{2}{*}{$2.568(1.816-3.632)$} \\
\hline Positive & 149 & 70.3 & 221 & 47.9 & & \\
\hline
\end{tabular}

Nasal Symptoms Plus Itchy Eyes

$\begin{array}{ccccccc}\text { Negative } & 87 & 41.0 & 278 & 60.3 & <0.0001 & 2.183(1.567-3.040) \\ \text { Positive } & 125 & 59.0 & 183 & 39.7 & & \end{array}$

\section{Time Of Occurrence}

$\begin{array}{lcccccc}\text { Unspecified } & 100 & 47.2 & 265 & 57.5 & 0.004^{\mathrm{a}} & 1.514(1.092-2.100)^{\mathrm{a}} \\ \text { Pollen Season } & 30 & 14.2 & 76 & 16.5 & & \\ \text { Perennial } & 82 & 38.7 & 120 & 26.0 & & \end{array}$

\section{Triggers}

\begin{tabular}{|c|c|c|c|c|c|c|}
\hline None & 57 & 26.9 & 189 & 41.0 & $0.002^{\mathrm{b}}$ & $1.890(1.324-2.697)$ \\
\hline Animals & 2 & 0.9 & 4 & 0.9 & & \\
\hline Pollens, House Dust (mites), Dust & 130 & 61.3 & 241 & 52.3 & & \\
\hline All of the Above & 23 & 10.8 & 27 & 5.9 & & \\
\hline
\end{tabular}

\section{Perceived Allergic Status}

$\begin{array}{ccccccc}\text { Negative } & 81 & 38.2 & 242 & 52.5 & <0.001 & 1.787(1.282-2.491) \\ \text { Positive } & 131 & 61.8 & 219 & 47.5 & \end{array}$

\section{Previous Allergic Test}

$\begin{array}{crrrrrr}\text { Negative } & 190 & 89.6 & 425 & 92.2 & \text { NS } & 1.367(0.783-2.387) \\ \text { Positive } & 22 & 10.4 & 36 & 7.8 & \end{array}$

\section{Result of the Allergic Test}

$\begin{array}{ccccccc}\text { Negative } & 9 & 45.0 & 16 & 47.1 & \text { NS } & 1.086(0.358-3.293) \\ \text { Positive } & 11 & 55.0 & 18 & 52.9 & \end{array}$

\section{Previous Medical Diagnosis}

$\begin{array}{ccccccc}\text { Negative } & 96 & 45.3 & 309 & 67.0 & <0.0001 & 2.456(1.761-3.427) \\ \text { Positive } & 116 & 54.7 & 152 & 33.0 & & \end{array}$

\section{Familial History Of Allergy}

$\begin{array}{ccccccc}\text { Negative } & 74 & 34.9 & 207 & 44.9 & 0.015 & 1.520(1.085-2.128) \\ \text { Positive } & 138 & 65.1 & 254 & 55.1 & \end{array}$


History with father

$\begin{array}{crrrrrrr}\text { Negative } & 153 & 72.2 & 366 & 79.4 & & \\ \text { Positive } & 59 & 27.8 & 95 & 20.6 & 0.038 & 1.486(1.020-2.163)\end{array}$

History with mother

$\begin{array}{crrrrrr}\text { Negative } & 138 & 65.1 & 330 & 71.6 & 0.089 & 1.351(0.954-1.912) \\ \text { Positive } & 74 & 34.9 & 131 & 28.4 & \end{array}$

History with son or daughter

$\begin{array}{crrrrrr}\text { Negative } & 150 & 70.8 & 347 & 75.3 & \text { NS } & 1.258(0.874-1.810) \\ \text { Positive } & 62 & 29.2 & 114 & 24.7 & \end{array}$

SFAR: Score for allergic rhinitis. RSI: Reflux symptom index. OR: Odds ratio. CI: confidence interval.

a $\mathrm{OR}$ was calculated between unspecific and specific with $\mathrm{P}=0.013$.

${ }^{\mathrm{b}}$ OR was calculated between none and other variables with $\mathrm{P}<0.001$.

TABLE 3

Comparing each RSI item with subjects with positive and negative SFAR

\begin{tabular}{|c|c|c|c|c|c|}
\hline RSI items & $\begin{array}{l}\text { Mean Scores in Subjects } \\
\text { with Positive SFAR } \pm \text { SD }\end{array}$ & $\begin{array}{l}\text { Percentage } \\
\text { (CI 95\%) }\end{array}$ & $\begin{array}{c}\text { Mean Scores in Subjects } \\
\text { with Negative SFAR } \pm \text { SD }\end{array}$ & $\begin{array}{l}\text { Percentage } \\
\text { (CI 95\%) }\end{array}$ & $P$ value \\
\hline Sore throat & $1.04 \pm 1.302$ & $0.90-1.18$ & $0.66 \pm 1.056$ & $0.55-0.78$ & $<0.001$ \\
\hline Sputum Production & $1.62 \pm 1.544$ & $1.47-1.79$ & $0.98 \pm 1.200$ & $0.86-1.11$ & $<0.001$ \\
\hline Excessive secretions & $1.67 \pm 1.586$ & $1.49-1.84$ & $0.84 \pm 1.226$ & $0.71-0.97$ & $<0.001$ \\
\hline Dysphagia & $1.10 \pm 1.416$ & $0.96-1.26$ & $0.57 \pm 1.090$ & $0.46-0.70$ & $<0.001$ \\
\hline $\begin{array}{l}\text { Coughing after Eating, Sleeping, } \\
\text { or Lying Down }\end{array}$ & $1.41 \pm 1.587$ & $1.25-1.57$ & $0.98 \pm 1.409$ & $0.84-1.14$ & $<0.001$ \\
\hline Breathing Difficulties & $1.38 \pm 1.529$ & $1.22-1.54$ & $0.71 \pm 1.189$ & $0.59-0.84$ & $<0.001$ \\
\hline Extreme Coughing Episodes & $1.37 \pm 1.594$ & $1.20-1.56$ & $0.94 \pm 1.464$ & $0.79-1.11$ & $<0.001$ \\
\hline $\begin{array}{c}\text { A Sense of Foreign Body in } \\
\text { Throat }\end{array}$ & $1.46 \pm 1.552$ & $1.30-1.62$ & $0.84 \pm 1.248$ & $0.70-0.98$ & $<0.001$ \\
\hline $\begin{array}{l}\text { Epigastric Burning Sense, Chest } \\
\text { Pain, Indigestion, and GERD }\end{array}$ & $1.96 \pm 1.732$ & $1.78-2.14$ & $1.41 \pm 1.467$ & $1.25-1.56$ & $<0.001$ \\
\hline Total Score & $13.00 \pm 9.705$ & $\begin{array}{c}11.93- \\
14.04\end{array}$ & $7.93 \pm 7.599$ & 7.19-8.76 & $<0.001$ \\
\hline
\end{tabular}

CI: Confidence interval. SFAR: Score for allergic rhinitis. RSI: Reflux symptom index. SD: Standard deviation. 


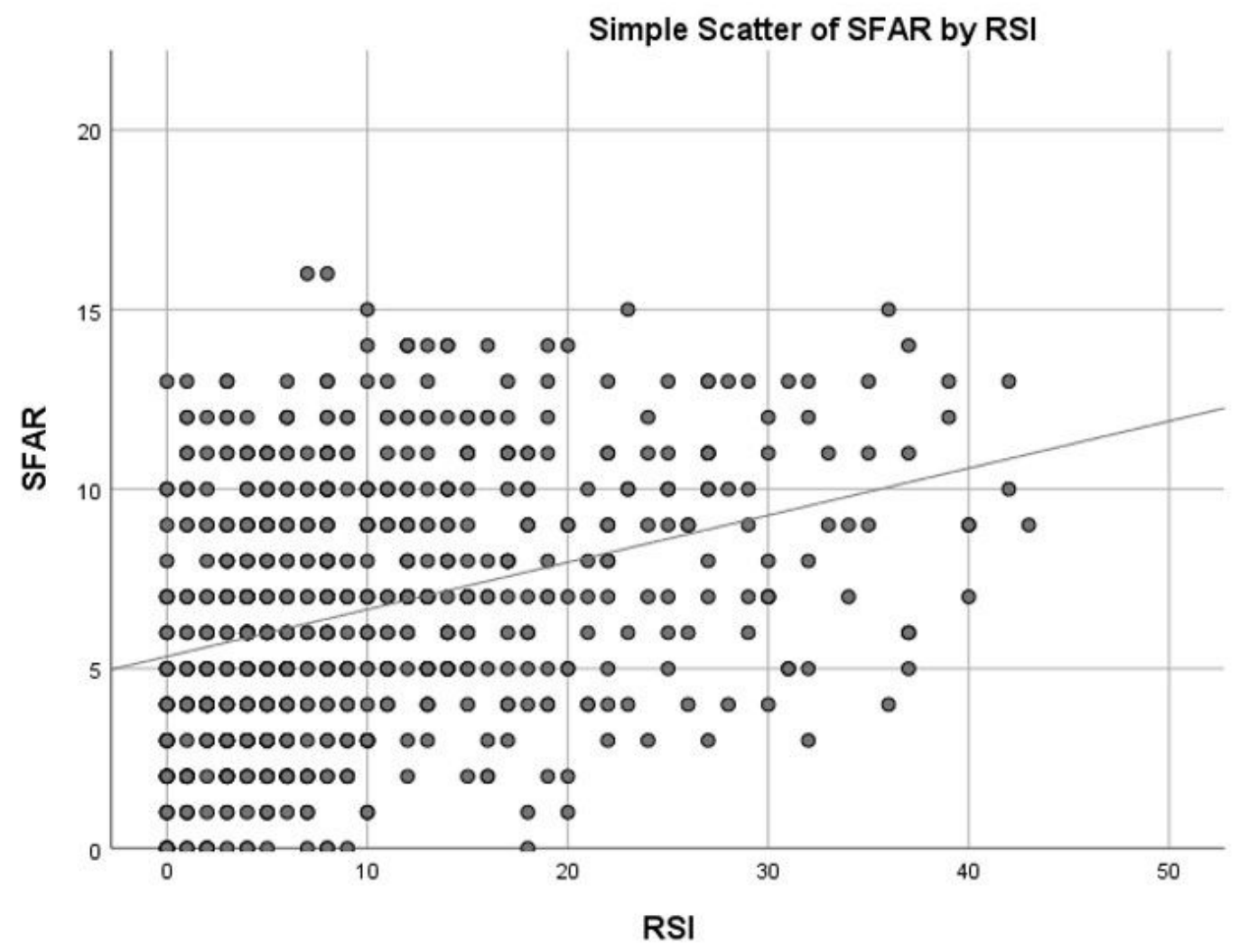

Figure 1

Showing the scatter of RSI and SFAR score values with $r=0.334$ at $P<0.01$. 


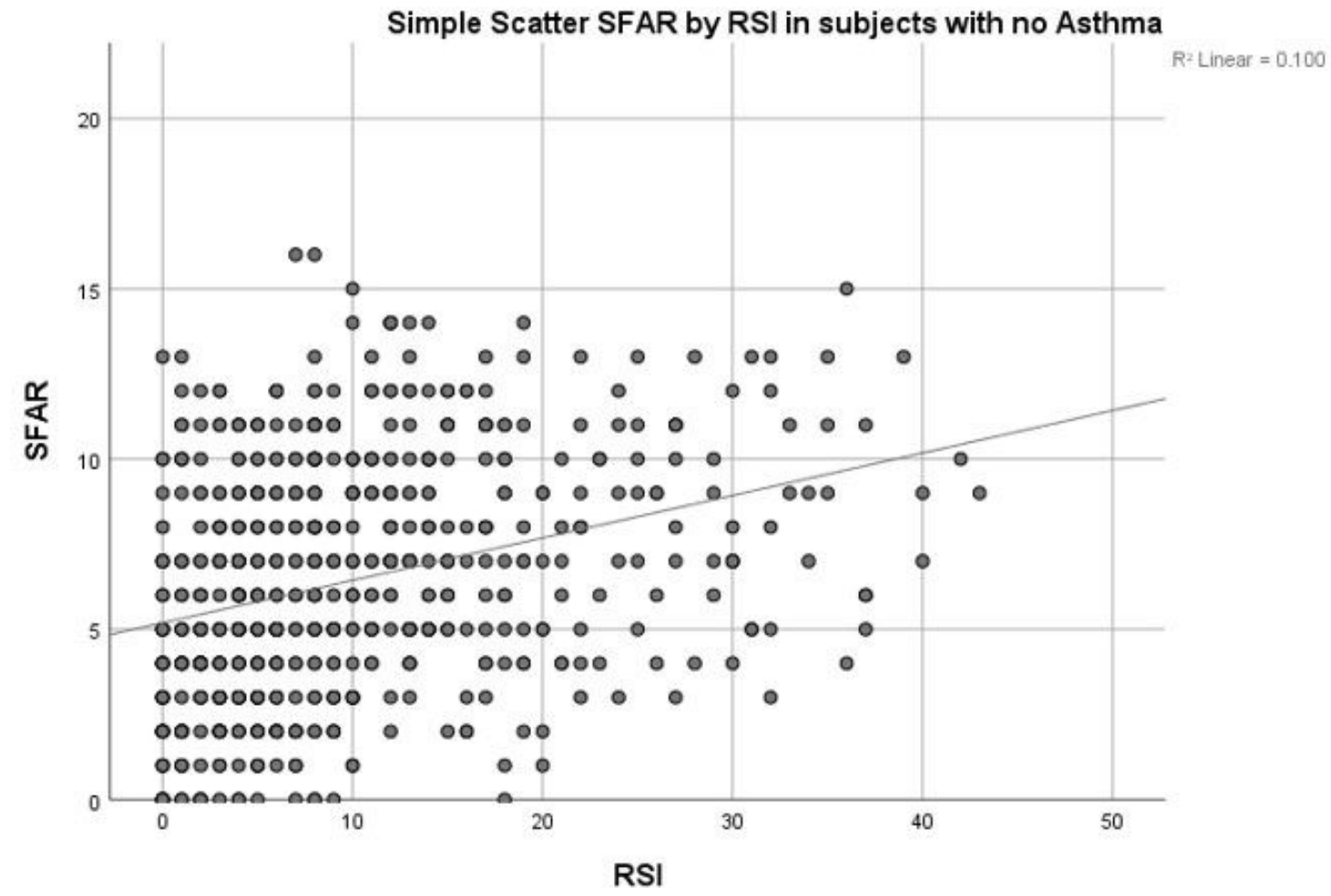

Figure 2

Showing the scatter of RSI and SFAR score values in subjects without asthma with $r=0.316$ at $P<0.01$. 